\title{
Original Article (short paper) \\ Efficacy of neurofunctional versus resistance training in improving gait and quality of life among patients with Parkinson's disease: a randomized clinical trial
}

\author{
Suhaila Mahmoud Smaili ${ }^{*}$, Maria Eduarda Brandão Bueno ${ }^{1}$, Natália Mariano Barboza ${ }^{1}$, Marcelle Brandão Terra ${ }^{1}$, \\ Isabela Andrelino de Almeida ${ }^{1}$, Henrique Ballalai Ferraz ${ }^{2}$ \\ ${ }^{1}$ Universidade Estadual de Londrina, UEL, Department of Physiotherapy, Londrina, PR, Brazil; \\ ${ }^{2}$ Universidade Federal de São Paulo, UNIFESP, Department of Neurology and Neurosurgery, São Paulo, SP, Brazil
}

\begin{abstract}
Aims: to compare the efficacy of neurofunctional training versus resistance training in improving gait and quality of life among patients with PD. Methods: This randomized controlled trial included 40 participants randomly assigned to two groups through random number table generator: resistance training (RT) (n=19) and neurofunctional training (NT) (n=21). The RT group performed resistance exercises emphasizing the lower limbs and trunk, while the NT group sessions were focused on gait, functional independence and balance training. Trained physical therapists supervised both groups. The training sessions lasted 60 minutes in each group and were performed twice a week, totalizing 24 sessions. The outcomes, gait and quality of life, were measured using video gait analysis and footprint analysis; and PDQL and PDQ-39 questionnaires, respectively. Results: intra-group comparison revealed all gait variables (stride length, step length, number of steps, time of distance walked, gait speed and cadence) improved after the NT intervention with large effect size, while only stride length improved in the RT group with moderate effect size. The between group analyses means $(\Delta)$ shows that all the variables presented statistically significant differences in the NT group. Additionally, both groups showed significant improvements in quality of life. Conclusions: The application of specific neurofunctional training, directed and enriched with sensorial resources, resulted in superior gait performance among individuals with PD when compared to those in the resistance training group; both treatments were efficacious in improving quality of life.
\end{abstract}

Keywords: parkinson disease; neurological rehabilitation; physical therapy modalities.

\section{Introduction}

Parkinson's disease (PD) is a progressive and degenerative disorder of dopaminergic neurons in the substantia nigra pars compacta that project to the striatum of the basal ganglia. PD is commonly associated with motor symptoms such as tremor, rigidity, postural instability and gait disorders, including gait slowness, festination, freezing of gait and poor postural control. A widespread supraspinal locomotor network including the cortex, cerebellum, basal ganglia, and brainstem contributes to the control of human locomotion, and altered activity of these structures underlies gait dysfunction due to PD. These impairments are associated with reduced quality of life, frequent falls, and complications from falls such as increased morbidity and mortality ${ }^{1}$.

Postural control involves maintaining, achieving and restoring a state of balance during movements and posture ${ }^{2}$ and it is clear that all three components of postural control are impaired in people with $\mathrm{PD}$ and affect their gait.

Besides that, bradykinesia and rigidity reduces steps size, upper extremity movement, axial trunk rotation and changing gait direction with a turn. The high muscle tonus and characteristic posture in excessive flexion of the hip, knees and ankles reduces lower limb joints torques, resulting in smaller steps and slower velocity ${ }^{3}$.

Nowadays the best treatment for PD is dopamine replacement therapy, but the effects of levodopa on balance and gait function in people with PD is controversial. For instance: hypokinesia (e.g., reduced step length, gait velocity, and arm swing) was the gait impairment most improved by levodopa. Interestingly, other measures of gait dysfunction, including gait timing and postural sway, were unaffected or even worsened, respectively, by levodopa ${ }^{4}$. As a result, new treatment approaches (mainly exercise therapy) are necessary and their effectiveness needs to be tested.

Recently, resistance training (RT) has been used in PD to improve the motor dysfunction inherent to the disease. Studies have reported the alleviation of motor symptoms, an increase in muscle strength, and improvements in mobility after a period of RT in patients with PD. Despite these benefits, the relationship with improved functional abilities such as gait among individuals with PD is not clear ${ }^{5-10}$. So, we don't know whether lower limb and trunk strengthening improves motor recruitment and joint torque in gait or not.

On the other hand, neurofunctional training (NT), that involves multi-strategies sources, has been used to improve balance and gait in PD. Challenging exercises with progressive difficulty, that include sensory integration, anticipatory postural adjustments, motor agility, stability limits, double task association, visual and auditory cues have been showed benefits $^{11-14}$. However, since retention and transfer of learning are significantly impaired in individuals with $\mathrm{PD}^{15}$, we don't know the real improvement in this kind of treatment. 
Even so, our hypothesis is based on the fact that maintain stable balance, make appropriate anticipatory postural adjustments prior to step initiation, generate speed and temporal coordination of gait, control trunk and arm displacements while walking and produce stable turns in walking direction is requirements to functional mobility. Therefore, this study's objective is to compare the efficacy of two treatment protocols in the improvement of gait among individuals with PD and the impact of these treatments on the quality of life of these individuals.

\section{Method}

\section{Design Overview / Setting}

This randomized clinical trial was conducted between February and August 2014 at the Londrina State University (UEL) in partnership with the Norte do Paraná University at the Laboratory of Functional Assessment and Human Motor Performance, together with CASA (Ágape Center of Social Support) in Londrina, Brazil.

\section{Randomization}

Patients were recruited and then allocated into one of the two groups randomly. The randomization procedure was done as follows: First, a random table of numbers was generated using the random sequence generator procedure (from the www. random.org website) considering 40 patients equally divided in two groups (resistance training or neurofunctional training); then, the sequence generated was included by an independent, blinded researcher into identical opaque sealed envelopes. Neither the patient nor the researcher was aware of possible group allocation until the opening of the envelope in front of the patient.

\section{Participants}

Sample size calculation was done using $\left(\mathrm{G}^{*}\right.$ Power version 3.1.9; Available at: http://www. gpower.hhu.de). Stride length was used as primary outcome based on a previous study ${ }^{16}$. Expecting to detect a difference in improvements between groups of 8.2 centimeters in stride length with a baseline standard deviation of 13.0 centimeters and using alpha of $5 \%, 40$ patients, divided into two groups, were necessary to obtain a power of $80 \%$.

A total of 62 individuals diagnosed with Parkinson's disease cared for by the Medical Outpatient Clinic of Neurology at the Hospital das Clínicas, State University of Londrina were recruited, 40 of which were randomized. Inclusion criteria were the following: (1) diagnosed with idiopathic PD, according to criteria provided by the UK Brain Bank ${ }^{17}$, (2) classified as Modified Hoehn \& Yahr Scale stage 1.5 to $3^{18}$, (3) at least 50 years of age, (4) able to walk independently, and (5) not enrolled in any other therapeutic program beyond taking medication. Exclusion criteria included individuals with other neurological or musculoskeletal diseases; associated disorders or cognitive disorders that could potentially interfere in the assessments and, finally, other exercise practices or preexisting diseases that could interfere in data collection or the therapeutic intervention. The medication regimens of all the patients remained the same throughout the entire experiment.

\section{Blinding}

No physical therapists engaged in the study (with the assistance of students in the physical therapy program) responsible for the interventions were involved in the assessments of gait and quality of life. Due to the nature of the interventions, the patients with PD were not blind in regard to the two types of training implemented in this study.

\section{Procedures}

All patients consented to participate in the study and signed free and informed consent forms. The study was approved by the Institutional Review Board at the State University of Londrina/ University Hospital (Report No. 028/2013), according to the standards established by the Consort-Statement ${ }^{19}$, registered with and approved by REBEC (Brazilian Clinical Trials Registry) under No. RBR-3p7zcf.

All procedures of study were performed with participants in the "on" stage of medication, by the same evaluator in the pre and post intervention. The first day of evaluation was for collecting:

Anthropometric data (Weight, Height and Body Mass Index).

Modified Hoehn \& Yahr Scale (HY): to assess the staging of the disease and impairment of individuals with $\mathrm{PD}^{18}$.

Unified Parkinson's Disease Rating Scale (UPDRS): assesses the progression of the disease according to its clinical characteristics. Only domains related to activities of daily living (part II) and the motor exam (part III), were used ${ }^{20}$.

Mini-Mental State Examination (MMSE): used to assess cognitive functions ${ }^{21}$. The score ranges from 0 to 30 , and the cutoff point is 24 .

The second day of evaluation was for collecting:

Footprint test: gait linear variables are assessed in this test. Each individual dips his/her feet in water-soluble ink and walks a distance of five meters on a paper walkway. The following variables were analyzed in the footprints, by two evaluators, with a ruler: base of support (distance between two feet), step length (distance between two consecutive contact points of opposite feet), and stride length (distance between successive points of contact of the same foot $)^{22}$.

Video gait analysis: the patient walks a 12-meter track maintaining a normal and confortable speed. The analysis takes into account the track's central 10 meters, disregarding the first and last meters, considered to be acceleration and deceleration distances. Time is timed in seconds and steps are counted. Gait speed is given by dividing space by time and the cadence of the number of steps by time.

Parkinson's Disease Quality of life - PDQL: consists of 37 items, divided into four categories: Parkinson's and systemic 
symptoms, emotional and social function. The highest score indicates the patient has a good perception of his/her quality of life ${ }^{23,24}$.

Parkinson's Disease Questionnaire - PDQ-39: presents 39 questions addressing eight dimensions of health for PD: mobility, activities of daily living, emotional wellbeing, stigma, social support, cognition, communication, and bodily discomfort. Scores range from 0 (no problem) to 100 (highest problem), i.e., a low score indicates a positive perception of health status ${ }^{25}$.

\section{Interventions}

After the groups were formed and assessments were implemented, the physical therapy intervention program was initiated. The intervention program consisted of two approaches: 1) resistance muscular training and 2) neurofunctional training. Both were performed by trained physical therapists in an adequate room with exercise equipment. The training sessions lasted 60 minutes and were performed twice a week, totaling 24 sessions (12 weeks).

\section{a) Resistance training group (RT)}

The RT intervention program took into account strengthening and stretching the main muscle groups of the lower limbs and trunk. The therapeutic sessions were divided into three blocs (sessions 1 to 8 , sessions 9 to 16 , and sessions 17 to 24 ), while repetitions and resistance of the exercises increased gradually from 1 to 2 series and from $1 \mathrm{~kg}$ to $2 \mathrm{kgs}$, respectively. The exercises were performed in two sets of 10 repetitions for resistance gain, in order to prevent patients from becoming too fatigued during sessions. A summary description of the RT intervention is shown in appendix 1 .

Appendix 1 - Intervention description of resistance training.

\begin{tabular}{|c|c|c|}
\hline 1 to 8 THERAPY & 9 to 16 THERAPY & 17 to 24 THERAPY \\
\hline \multicolumn{3}{|c|}{ Objective: muscle strengthening and stretching } \\
\hline $\begin{array}{l}2 \text { series of } 10 \text { repetitions of each exercise } \\
\text { described below with } 1.0 \mathrm{~kg} \text { dumbbell }\end{array}$ & $\begin{array}{l}2 \text { series of } 10 \text { repetitions of each exercise } \\
\text { described with } 1.5 \mathrm{~kg} \text { dumbbell }\end{array}$ & $\begin{array}{l}2 \text { series of } 10 \text { repetitions of each exercise } \\
\text { described with } 2.0 \mathrm{~kg} \text { dumbbell }\end{array}$ \\
\hline Exercises performed in the supine position: & Exercises performed in the supine position: & Exercises performed in the supine position: \\
\hline 1) Lower limbs triple flexion on the trunk & 1) Lower limbs triple flexion on the trunk & 1) Lower limbs triple flexion on the trunk \\
\hline $\begin{array}{l}\text { 2) Two-leg stance with lower limbs supported } \\
\text { on a ball }\end{array}$ & $\begin{array}{l}\text { 2) Two-leg stance with lower limbs supported } \\
\text { on a ball }\end{array}$ & $\begin{array}{l}\text { 2) Two-leg stance with lower limbs supported } \\
\text { on a ball }\end{array}$ \\
\hline $\begin{array}{l}\text { 3) Two-leg stance with biceps strengthening } \\
\text { (elbow flexion) and pectoral strengthening } \\
\text { (shoulder abduction and adduction) with } \\
\text { lower limbs supported on a ball }\end{array}$ & $\begin{array}{l}\text { 3) Two-leg stance with biceps strengthening } \\
\text { (elbow flexion) and pectoral strengthening } \\
\text { (shoulder abduction and adduction) with } \\
\text { lower limbs supported on a ball }\end{array}$ & $\begin{array}{l}\text { 3) Two-leg stance with biceps strengthening } \\
\text { (elbow flexion) and pectoral strengthening } \\
\text { (shoulder abduction and adduction) with } \\
\text { lower limbs supported on a ball }\end{array}$ \\
\hline $\begin{array}{l}\text { 4) Single-leg stance with lower limbs flexed } \\
\text { on a ball }\end{array}$ & $\begin{array}{l}\text { 4) Single leg stance with lower limbs flexed } \\
\text { on a ball }\end{array}$ & $\begin{array}{l}\text { 4) Single leg stance with lower limbs flexed } \\
\text { on a ball }\end{array}$ \\
\hline $\begin{array}{l}\text { 5) Strengthening of upper limbs: triceps, } \\
\text { biceps, deltoid, and pectoral }\end{array}$ & $\begin{array}{l}\text { 5) Strengthening of upper limbs: triceps, } \\
\text { biceps, deltoid, and pectoral }\end{array}$ & $\begin{array}{l}\text { 5) Strengthening of upper limbs: triceps, } \\
\text { biceps, deltoid, and pectoral }\end{array}$ \\
\hline $\begin{array}{l}\text { 6) Bilateral single-leg stance with lower limbs } \\
\text { supported on a ball }\end{array}$ & $\begin{array}{l}\text { 6) Bilateral single leg stance with lower limbs } \\
\text { supported on a ball }\end{array}$ & $\begin{array}{l}\text { 6) Bilateral single leg stance with lower limbs } \\
\text { supported on a ball }\end{array}$ \\
\hline $\begin{array}{l}\text { 7) Strengthening of abdominal muscles (rec- } \\
\text { tus and oblique) }\end{array}$ & $\begin{array}{l}\text { 7) Strengthening of abdominal muscles (rec- } \\
\text { tus and oblique) }\end{array}$ & $\begin{array}{l}\text { 7) Strengthening of abdominal muscles (rec- } \\
\text { tus and oblique) }\end{array}$ \\
\hline $\begin{array}{l}\text { 8) Strengthening of lower limbs: hip flexors, } \\
\text { knee extensors and dorsiflexors }\end{array}$ & $\begin{array}{l}\text { 8) Strengthening of lower limbs: hip flexors, } \\
\text { knee extensors and dorsiflexors }\end{array}$ & $\begin{array}{l}\text { 8) Strengthening of lower limbs: hip flexors, } \\
\text { knee extensors and dorsiflexors }\end{array}$ \\
\hline $\begin{array}{l}\text { Exercises performed in lateral decubitus } \\
\text { position: }\end{array}$ & $\begin{array}{l}\text { Exercises performed in lateral decubitus } \\
\text { position: }\end{array}$ & $\begin{array}{l}\text { Exercises performed in lateral decubitus } \\
\text { position: }\end{array}$ \\
\hline $\begin{array}{l}\text { 9) Strengthening of hip abductors and adduc- } \\
\text { tors }\end{array}$ & $\begin{array}{l}\text { 9) Strengthening of hip abductors and adduc- } \\
\text { tors }\end{array}$ & $\begin{array}{l}\text { 9) Strengthening of hip abductors and adduc- } \\
\text { tors }\end{array}$ \\
\hline $\begin{array}{l}\text { 10) Triple flexion of lower limbs associated } \\
\text { with shoulder flexion and extension }\end{array}$ & $\begin{array}{l}\text { 10) Triple flexion of lower limbs associated } \\
\text { with shoulder flexion and extension }\end{array}$ & $\begin{array}{l}\text { 10) Triple flexion of lower limbs associated } \\
\text { with shoulder flexion and extension }\end{array}$ \\
\hline $\begin{array}{l}\text { 11) Strengthening of shoulder muscles and } \\
\text { girdle }\end{array}$ & $\begin{array}{l}\text { 11) Strengthening of shoulder muscles and } \\
\text { girdle }\end{array}$ & $\begin{array}{l}\text { 11) Strengthening of shoulder muscles and } \\
\text { girdle }\end{array}$ \\
\hline Sitting on a chair: & Sitting on a chair: & Sitting on a chair: \\
\hline $\begin{array}{l}\text { 12) Strengthening hip flexors and knee } \\
\text { extensors }\end{array}$ & $\begin{array}{l}\text { 12) Strengthening hip flexors and knee } \\
\text { extensors }\end{array}$ & $\begin{array}{l}\text { 12) Strengthening hip flexors and knee } \\
\text { extensors }\end{array}$ \\
\hline 13) Anterior trunk flexion, back strengthening & 13) Anterior trunk flexion, back strengthening & 13) Anterior trunk flexion, back strengthening \\
\hline $\begin{array}{l}\text { 14) Transition from sitting to standing associ- } \\
\text { ating elbow and shoulder flexion }\end{array}$ & $\begin{array}{l}\text { 14) Transition from sitting to standing asso- } \\
\text { ciating elbow and shoulder flexion }\end{array}$ & $\begin{array}{l}\text { 14) Transition from sitting to standing asso- } \\
\text { ciating elbow and shoulder flexion }\end{array}$ \\
\hline Standing: & Standing: & Standing: \\
\hline $\begin{array}{l}\text { 15) Strengthening of knee flexors and upper } \\
\text { limbs supported on chair }\end{array}$ & $\begin{array}{l}\text { 15) Strengthening of knee flexors and upper } \\
\text { limbs supported on chair }\end{array}$ & $\begin{array}{l}\text { 15) Strengthening of knee flexors and upper } \\
\text { limbs supported on chair }\end{array}$ \\
\hline $\begin{array}{l}\text { Strengthening calf with plantar flexion and } \\
\text { upper limbs supported on chair }\end{array}$ & $\begin{array}{l}\text { Strengthening calf with plantar flexion and } \\
\text { upper limbs supported on chair }\end{array}$ & $\begin{array}{l}\text { Strengthening calf with plantar flexion and } \\
\text { upper limbs supported on chair }\end{array}$ \\
\hline
\end{tabular}




\section{b) Neurofunctional training group (NT)}

The protocol of the NT intervention took into account balance training, sensory integration, agility, and motor coordination, stability limits, anticipatory and reactive postural adjustments, functional independence, and gait improvement. The therapy sessions were divided into three blocs (sessions 1 to 8 , sessions 9 to 16 , and sessions 17 to 24), in which the complexity of exercises increased gradually, such as the support base (from a more stable to a less stable base), more unstable therapeutic resources were used (such as balls and trampolines), exercises were associated with gains in agility and motor coordination among the upper limbs, lower limbs and trunk, and gait circuits were developed. A summary description of the TN intervention is presented in appendix 2.

Appendix 2 - Intervention description neurofunctional training.

\begin{tabular}{|c|c|c|}
\hline 1 to 8 THERAPY & 9 to 16 THERAPY & 17 to 24 THERAPY \\
\hline \multicolumn{3}{|c|}{ Objective: Balance training and sensory integration } \\
\hline Foam exercises & Foam exercises & Foam exercises \\
\hline $\begin{array}{l}\text { 1. OE/CE Romberg wide/narrow base } \\
\text { 2. Romberg associated with upper and lower } \\
\text { limbs focusing on speed of movement, ampli- } \\
\text { tude and postural transitions. } \\
\text { 3. Romberg with exercises varying weight } \\
\text { shifts with step on lateral associating upper } \\
\text { and lower limbs }\end{array}$ & $\begin{array}{l}\text { 1. Bilateral OE/CE tandem } \\
\text { 2. Tandem associated with upper and lower } \\
\text { limbs exercises focusing on speed of move- } \\
\text { ment, amplitude, and postural transitions } \\
\text { 3. Tandem associated with trunk exercises } \\
\text { focusing on the speed of movement, amplitu- } \\
\text { de and postural transitions } \\
\text { 4. Tandem with exercises varying weight } \\
\text { transference with step forward, side and rear } \\
\text { associating upper and lower limbs movement }\end{array}$ & $\begin{array}{l}\text { 1. Single-leg stance OE bilateral } \\
\text { 2. Single-leg stance associated with upper } \\
\text { and lower limbs exercises focusing on the } \\
\text { speed of movement, amplitude and postural } \\
\text { transitions } \\
\text { 3. Single-leg stance associated with trunk } \\
\text { exercises focusing on speed of movement, } \\
\text { amplitude and postural transitions } \\
\text { 4. Single-leg: slide a lower limb forward and } \\
\text { back and then make a circular movement } \\
\text { bilaterally }\end{array}$ \\
\hline \multicolumn{3}{|c|}{ Objective: Balance training, agility and motor coordination } \\
\hline Exercises on a step bench & Exercises on a step bench & Exercises on a step bench \\
\hline $\begin{array}{l}\text { 1. Step on the step bench changing the mo- } \\
\text { vement sequences to stimulate coordination, } \\
\text { stability limits and postural adjustments. }\end{array}$ & $\begin{array}{l}\text { 1. Step on the step bench changing the move- } \\
\text { ment sequences to stimulate motor coordina- } \\
\text { tion (more complex), stimulate stability and } \\
\text { postural adjustments. Sequence of exercises } \\
\text { using single-leg support and sequence of exer- } \\
\text { cises associated with upper limbs movement }\end{array}$ & $\begin{array}{l}\text { 1. Step on the step bench changing the } \\
\text { movement sequences to stimulate motor } \\
\text { coordination (even more complex), stimula- } \\
\text { ting stability limits and postural adjustments. } \\
\text { Sequence of exercises using single-leg } \\
\text { support, maintenance of single-leg support } \\
\text { in the sequences and sequence of exercises } \\
\text { associated with upper limbs movement (more } \\
\text { complex) }\end{array}$ \\
\hline
\end{tabular}

Objective: Balance training, stability limits, anticipatory and reactive adjustments

\begin{tabular}{lll}
\hline TRAMPOLIM & TRAMPOLIM & TRAMPOLIM \\
\hline $\begin{array}{ll}\text { 1. Exercise in Romberg position stimulating } \\
\text { side-to-side weight shifts }\end{array}$ & $\begin{array}{l}\text { 1. Exercise in Tandem position stimulating } \\
\text { anterior-posterior weight shifts }\end{array}$ & $\begin{array}{l}\text { 1. Exercise in single-leg stance changing the } \\
\text { position of the center of body gravity }\end{array}$ \\
$\begin{array}{ll}\text { 2. Exercises in Romberg position stepping } \\
\text { forward, side and rear bilaterally }\end{array}$ & $\begin{array}{l}\text { 2. Exercise in Romberg and Tandem positions } \\
\text { associating trunk flexion, extension, and rota- }\end{array}$ & $\begin{array}{l}\text { 2. Exercises in the single-leg stance associa- } \\
\text { ting upper limbs movement }\end{array}$ \\
$\begin{array}{l}\text { 3. Exercise in Romberg performing knew } \\
\text { tlexion and extension to change the center of associated upper limbs movement } \\
\text { body gravity. }\end{array}$ & $\begin{array}{ll}\text { 3. Introduction of short hops in Romberg. } \\
\text { 3. Intion of short hops in Romberg. }\end{array}$ \\
\hline
\end{tabular}

Objective: Balance training, stimulus to transitions of posture and functional independence

BALL BALL BALL

1. Facilitate transition of posture from sitting on heels to kneeling and from knelling to semi-kneeling, with and without trunk rotation holding a Bobath ball

2. In semi-kneeling position, facilitating trunk anterior displacement, pushing a Bobath ball forward

\section{Same as before plus:}

1. In semi-kneeling position, associating trunk rotation and upper limbs movement

2. In semi-kneeling position, facilitating transition from semi-kneeling to standing
Same as before plus:

1. Exercise with patient sitting on a ball with one-leg support elevating the other lower limb, keeping the position for 10 seconds
Gait training with com circuit 1
Gait training with com circuit 2 - increasing level of difficulty in comparison to 1
Gait training with com circuit 3 - increasing level of difficulty in comparison to 1 and 2 
At the end of the study, the groups were submitted to another battery of assessments composed of the same tests and instruments used in the pre-intervention assessment.

\section{Statistical Analysis}

Descriptive analysis of data is expressed by mean, standard deviation or median and interquartile interval according to the distribution of normality of data verified by the ShapiroWilk test. The two groups were compared using the Student- $t$ test and pre- and post-interventions were compared using the paired-samples t-test. Cohen's d effect size measures (ES) were used to determine the magnitude of post intervention changes (ES $=$ difference between post and pre intervention mean divided by pre-intervention standard deviation). The values used to interpret the effect size ${ }^{26}$ were: insignificant $<0.19$, small 0.20 -0.49 , average $0.50-0.79$, large $0.80-1.29$, and very large $>1.30$. For data to be considered statistically significant, a level of significance of $5 \%$ was adopted. The analysis was conducted using the SPSS version 20.

\section{Results}

Sixty-two patients were admitted in the study and 40 met the eligibility criteria: 19 were assigned to the resistance-training (RT) group and 21 were assigned to the neurofunctional training (NT) group. Figure 1 represents the algorithm progression of patients in the clinical trial.

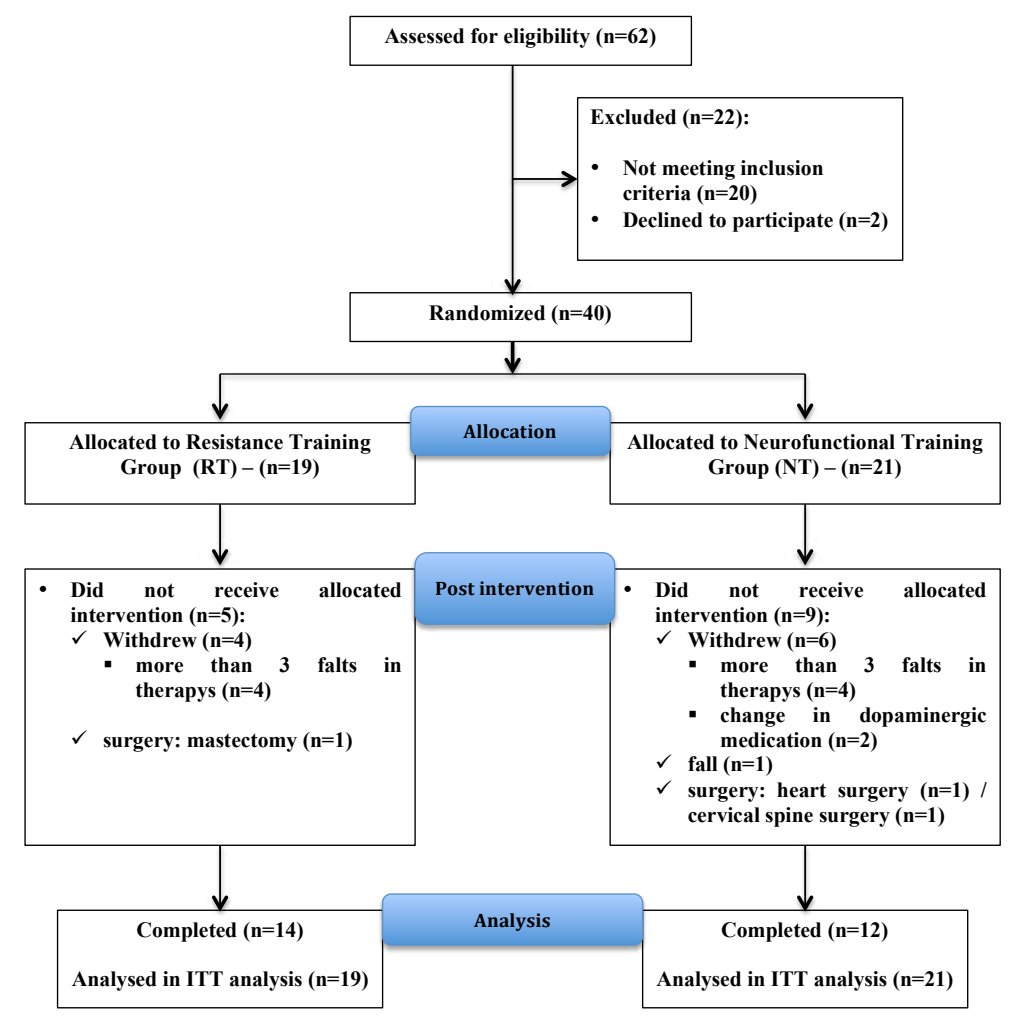

The group's initial characteristics are presented in Table 1. The values are expressed in terms of mean and standard deviation. The groups were homogeneous in the initial assessment in regard to age, weight, height, BMI, H\&Y staging, UPDRS and MMSE scores and also in regard to diagnosis.

Table 1. Characteristics of participants.

\begin{tabular}{lccc}
\hline \multicolumn{1}{c}{ Variables } & RT Group & NT Group & P \\
Age (years) & $67.0(7.9)$ & $68.5(6.5)$ & 0.37 \\
Weight $(\mathrm{kg})$ & $76.6(14.6)$ & $74.5(17.1)$ & 0.64 \\
Height $(\mathrm{m})$ & $1.68(0.07)$ & $1.64(0.07)$ & 0.76 \\
BMI $\left(\mathrm{kg} / \mathrm{m}^{2}\right)$ & $26.9(5.2)$ & $27.4(5.8)$ & 0.42 \\
H\&Y & $2.3(0.5)$ & $2.2(0.6)$ & 0.17
\end{tabular}

\begin{tabular}{lccc} 
UPDRS (ADL) & $9.9(3.6)$ & $9.5(4.4)$ & 0.91 \\
UPDRS (motor) & $21.7(8.5)$ & $21.3(8.6)$ & 0.77 \\
UPDRS (total) & $31.7(11.3)$ & $30.9(12.4)$ & 0.95 \\
MMSE & $27.8(2.2)$ & $27.2(2.1)$ & 0.70 \\
Years diagnosed with PD & $5.6(4.2)$ & $5.4(5.3)$ & 0.87 \\
\hline
\end{tabular}

Data presented as mean values \pm SD. No significant differences between groups $(\mathrm{p}>0.05)$.

RT: resistance training; NT: neurofunctional training; BMI: Body Mass Index; H\&Y: Modified Hoehn\&Yahr Scale; UPDRS: Unified Parkinson's Disease Rating Scale; ADL: activities of daily living; MMSE: Mini-Mental State Examination.

Table 2 presents the scores of the items assessed before and after RT and NT interventions, obtained through the footprint test and video gait analysis. The intra-group analysis shows statistically significant improvement for both the RT and NT 
groups in regard to stride length, though improvement was considerably greater in the NT, as shown by the effect size ( $E S=0.41 \times 3.20$ ); i.e., it improved $33.2 \%$ for NT, compared to only $6.5 \%$ in RT group. Additionally, stride length was significantly larger only in the NT group and represented a $35 \%$ post-intervention improvement. The video gait analysis shows significant improvement for all the variables studied in NT: the number of steps improved by $18.3 \%$; time of distance walked improved by $27.3 \%$; gait speed by $36.7 \%$; and cadence by $11.8 \%$. Such improvements, however, did not occur in the RT group, as no difference was found between the initial and final scores obtained by this group. The analysis concerning inter-group means $(\Delta)$ revealed statistically significant differences for all the variables concerning the NT group.

Table 2. Footprint test and video gait analysis results.

\begin{tabular}{|c|c|c|c|c|c|c|c|c|c|c|}
\hline \multirow[b]{2}{*}{ Variables } & \multicolumn{5}{|c|}{ RT Group } & \multicolumn{5}{|c|}{ NT Group } \\
\hline & Pre & Post & $\mathbf{P}$ & $\Delta$ & ES & Pre & Post & $\mathbf{P}$ & $\Delta$ & ES \\
\hline Stride length $(\mathrm{cm})$ & $\begin{array}{l}103.3 \\
(16.5)\end{array}$ & $\begin{array}{c}110.1 \\
(13.2)\end{array}$ & $0.002^{*}$ & $6.8(3.0 ; 10.6)$ & 0.41 & $\begin{array}{l}109.3 \\
(11.4)\end{array}$ & $\begin{array}{l}145.6 \\
(8.4)\end{array}$ & $0.000^{*}$ & $36.3(28.6 ; 44.0)^{\#}$ & 3.20 \\
\hline Step length (cm) & $\begin{array}{l}53.3 \\
(8.6)\end{array}$ & $\begin{array}{l}54.1 \\
(7.1)\end{array}$ & 0.61 & $0.8(-2.6 ; 4.2)$ & - & $\begin{array}{l}54.2 \\
(7.3)\end{array}$ & $\begin{array}{l}73.3 \\
(3.9)\end{array}$ & $0.000^{*}$ & $19.0(14.6 ; 23.6)^{\#}$ & 2.62 \\
\hline Number of steps & $\begin{array}{l}15.5 \\
(2.1)\end{array}$ & $\begin{array}{l}15.6 \\
(1.7)\end{array}$ & 0.97 & $0.0(-0.8 ; 0.8)$ & - & $\begin{array}{l}15.3 \\
(1.7)\end{array}$ & $\begin{array}{l}12.5 \\
(1.0)\end{array}$ & $0.000^{*}$ & $-2.8(-3.7 ;-1.9)^{\#}$ & -1.65 \\
\hline Time of distance walked (s) & $\begin{array}{c}9.1 \\
(1.4)\end{array}$ & $\begin{array}{l}9.21 \\
(1.1)\end{array}$ & 0.86 & $0.07(-0.7 ; 0.9)$ & - & $\begin{array}{c}8.8 \\
(1.1)\end{array}$ & $\begin{array}{c}6.4 \\
(0.9)\end{array}$ & $0.000^{*}$ & $-2.4(-3.2 ;-1.6)^{\#}$ & -2.18 \\
\hline Gait speed $(\mathrm{m} / \mathrm{s})$ & $\begin{array}{c}1.1 \\
(0.2)\end{array}$ & $\begin{array}{c}1.1 \\
(0.1)\end{array}$ & 0.70 & $-0.01(-0.1 ; 0.0)$ & - & $\begin{array}{c}1.1 \\
(0.1)\end{array}$ & $\begin{array}{c}1.6 \\
(0.2)\end{array}$ & $0.000 *$ & $0.5(0.2 ; 0.5)^{\#}$ & 5.00 \\
\hline Cadence (steps/s) & $\begin{array}{l}1.71 \\
(0.2)\end{array}$ & $\begin{array}{l}1.7 \\
(0.2)\end{array}$ & 0.75 & $-0.01(-0.1 ; 0.1)$ & - & $\begin{array}{l}1.7 \\
(0.2)\end{array}$ & $\begin{array}{l}2.0 \\
(0.2)\end{array}$ & $0.006^{*}$ & $0.2(0.1 ; 0.4)^{\#}$ & 1.50 \\
\hline
\end{tabular}

$\mathrm{ES}=$ Effect Size; $\mathrm{cm}=$ centimeter; $\mathrm{s}=$ seconds; $\mathrm{m} / \mathrm{s}=$ meters per second $; *$ = intragroup difference; $\#=\mathrm{P}<0.05$ versus RT Group

$\%$ stride length improvement: RT $-6.8 / 103.3=6.5 \% / \mathrm{BT}-36.3 / 109.3=33.2 \%$

$\%$ step length improvement: RT $-0.8 / 53.3=1.5 \% / \mathrm{BT}-19.0 / 54.2=35.0 \%$

$\%$ number of steps improvement: BT $-2.8 / 15.3=18.3 \%$

$\%$ time of distance walked improvement: $\mathrm{BT}-2.4 / 8.8=27.3 \%$

$\%$ gait speed improvement: $\mathrm{BT}-0.4 / 1.1=36.7 \%$

$\%$ cadence improvement: $\mathrm{BT}-0.2 / 1.7=11.8 \%$

Table 3 presents the scores obtained before and after the RT and NT interventions using the PDQL. The intra-group analysis presented statistically significant improvement for all the domains in the NT questionnaire and for the domains: Parkinson's symptoms, Systemic Symptoms, and the PDQL's total score for the RT group. The magnitude of values concerning effect size was greater for the NT. No statistically significant differences were found in the analysis of the inter-group means $(\Delta)$.

Table 3. Parkinson's Disease Quality of life (PDQL) results.

\begin{tabular}{|c|c|c|c|c|c|c|c|c|c|c|}
\hline \multirow[b]{2}{*}{ Variables } & \multicolumn{5}{|c|}{ RT Group } & \multicolumn{5}{|c|}{ NT Group } \\
\hline & Pre & Post & $\mathbf{P}$ & $\Delta$ & ES & Pre & Post & $\mathbf{P}$ & $\Delta$ & ES \\
\hline Total score & $\begin{array}{c}72.8 \\
(14.8)\end{array}$ & $\begin{array}{c}78.2 \\
(13.7)\end{array}$ & $0.01 *$ & $5.3(1.1 ; 9.5)$ & 0.36 & $\begin{array}{c}68.3 \\
(14.6)\end{array}$ & $\begin{array}{c}75.7 \\
(16.4)\end{array}$ & $0.001 *$ & $7.5(3.3 ; 11.7)$ & 0.51 \\
\hline Parkinsonian symptoms & $\begin{array}{c}70.1 \\
(15.4)\end{array}$ & $\begin{array}{c}77.6 \\
(12.8)\end{array}$ & $0.01^{*}$ & $7.5(1.4 ; 13.7)$ & 0.49 & $\begin{array}{c}64.4 \\
(14.9)\end{array}$ & $\begin{array}{c}71.1 \\
(19.0)\end{array}$ & $0.001 *$ & $7.7(3.7 ; 11.6)$ & 0.52 \\
\hline Sistemyc symptoms & $\begin{array}{c}67.8 \\
(20.4)\end{array}$ & $\begin{array}{c}73.7 \\
(19.4)\end{array}$ & $0.02 *$ & $5.8(0.9 ; 10.8)$ & 0.28 & $\begin{array}{c}65.7 \\
(20.4)\end{array}$ & $\begin{array}{c}73.9 \\
(20.7)\end{array}$ & $0.009 *$ & $7.5(2.1 ; 12.9)$ & 0.37 \\
\hline Emocional functioning & $\begin{array}{c}77.7 \\
(15.7)\end{array}$ & $\begin{array}{c}81.1 \\
(12.9)\end{array}$ & 0.10 & $3.3(-0.7 ; 7.4)$ & 0.21 & $\begin{array}{c}69.8 \\
(17.5)\end{array}$ & $\begin{array}{c}78.6 \\
(15.7)\end{array}$ & $0.003 *$ & $8.6(3.3 ; 14.0)$ & 0.49 \\
\hline Social functioning & $\begin{array}{c}77.1 \\
(18.1)\end{array}$ & $\begin{array}{c}79.9 \\
(19.1)\end{array}$ & 0.39 & $2.8(-4.1 ; 9.8)$ & 0.15 & $\begin{array}{c}76.7 \\
(16.1)\end{array}$ & $\begin{array}{c}83.0 \\
(16.1)\end{array}$ & $0.03 *$ & $6.0(0.5 ; 11.4)$ & 0.37 \\
\hline
\end{tabular}

$\mathrm{ES}=$ Effect Size; $*$ = intragroup difference.

Table 4 presents the scores obtained before and after the RT and NT interventions using the PDQ-39. Intra-group analysis presents statistically significant improvement in the total score and in the domains: mobility, ADL and emotional well-being in the RT group. The NT group obtained statistically significant improvement in the total score and in the domains: ADL and emotional wellbeing. No statistically significant differences were found in the analysis concerning the inter-group means $(\Delta)$. 
Table 4. Parkinson's Disease Questionnaire (PDQ-39) results.

\begin{tabular}{|c|c|c|c|c|c|c|c|c|c|c|}
\hline \multirow[b]{2}{*}{ Variables } & \multicolumn{5}{|c|}{ RT Group } & \multicolumn{5}{|c|}{ NT Group } \\
\hline & Pre & Post & $\mathbf{P}$ & $\Delta$ & ES & Pre & Post & $\mathbf{P}$ & $\Delta$ & ES \\
\hline Total score & $\begin{array}{c}27.4 \\
(12.4)\end{array}$ & $\begin{array}{c}19.1 \\
(10.9)\end{array}$ & $0.003^{*}$ & $-8.3(-13.3 ;-3.1)$ & -0.67 & $\begin{array}{c}27.2 \\
(17.7)\end{array}$ & $\begin{array}{c}22.3 \\
(17.7)\end{array}$ & $0.02 *$ & $-5.1(-9.5 ;-0.8)$ & -0.29 \\
\hline Mobility & $\begin{array}{c}28.3 \\
(23.3)\end{array}$ & $\begin{array}{l}19.5 \\
(23.0)\end{array}$ & $0.006^{*}$ & $-8.8(-14.7 ;-2.9)$ & -0.38 & $\begin{array}{l}26.0 \\
(24.4)\end{array}$ & $\begin{array}{l}21.3 \\
(25.3)\end{array}$ & 0.09 & $-4.8(-10.6 ; 0.9)$ & -0.20 \\
\hline $\mathrm{ADL}$ & $\begin{array}{l}35.5 \\
(24.3)\end{array}$ & $\begin{array}{c}20.5 \\
(18.0)\end{array}$ & $0.01 *$ & $-14.9(-25.9 ;-3.9)$ & -0.61 & $\begin{array}{c}33.3 \\
(29.3)\end{array}$ & $\begin{array}{c}24.7 \\
(25.0)\end{array}$ & $0.04 *$ & $-9.2(-18.0 ;-0.3)$ & -0.31 \\
\hline Emocional well-being & $\begin{array}{c}30.3 \\
(19.2)\end{array}$ & $\begin{array}{c}22.0 \\
(14.7)\end{array}$ & $0.02 *$ & $-8.3(-15.1 ;-1.4)$ & -0.43 & $\begin{array}{c}29.1 \\
(21.5)\end{array}$ & $\begin{array}{c}23.5 \\
(20.8)\end{array}$ & $0.04 *$ & $-5.2(-10.6 ;-0.8)$ & -0.24 \\
\hline Stigma & $\begin{array}{c}8.5 \\
(10.8)\end{array}$ & $\begin{array}{c}7.3 \\
(10.4)\end{array}$ & 0.67 & $-1.1(-6.5 ; 4.3)$ & -0.10 & $\begin{array}{c}14.3 \\
(12.6)\end{array}$ & $\begin{array}{c}12.5 \\
(13.4)\end{array}$ & 0.20 & $-1.9(-5.1 ; 1.2)$ & -0.15 \\
\hline Social support & $\begin{array}{c}12.2 \\
(18.6)\end{array}$ & $\begin{array}{c}6.3 \\
(17.5)\end{array}$ & 0.20 & $-5.8(-15.3 ; 3.5)$ & -0.31 & $\begin{array}{c}7.3 \\
(17.1)\end{array}$ & $\begin{array}{c}4.9 \\
(11.4)\end{array}$ & 0.56 & $-2.2(-9.9 ; 5.5)$ & -0.13 \\
\hline Cognitions & $\begin{array}{c}31.2 \\
(22.7)\end{array}$ & $\begin{array}{c}26.4 \\
(19.4)\end{array}$ & 0.35 & $-4.7(-15.3 ; 5.7)$ & -0.21 & $\begin{array}{c}39.3 \\
(25.4)\end{array}$ & $\begin{array}{c}34.1 \\
(27.2)\end{array}$ & 0.11 & $-6.9(-15.5 ; 1.7)$ & -0.27 \\
\hline Communication & $\begin{array}{c}22.0 \\
(25.1)\end{array}$ & $\begin{array}{c}11.2 \\
(15.5)\end{array}$ & 0.05 & $-10.7(-21.1 ; 0.1)$ & -0.43 & $\begin{array}{l}24.0 \\
(21.0)\end{array}$ & $\begin{array}{l}23.0 \\
(21.5)\end{array}$ & 0.89 & $-1.0(-7.0 ; 6.1)$ & -0.05 \\
\hline Bodily discomfort & $\begin{array}{l}43.8 \\
(20.3)\end{array}$ & $\begin{array}{c}35.7 \\
(20.5)\end{array}$ & 0.08 & $-7.8(-16.9 ; 1.3)$ & -0.38 & $\begin{array}{c}39.2 \\
(34.2)\end{array}$ & $\begin{array}{c}33.3 \\
(29.6)\end{array}$ & 0.10 & $-7.4(-16.7 ; 1.8)$ & -0.22 \\
\hline
\end{tabular}

$\mathrm{ES}=$ Effect Size; $\mathrm{ADL}=$ activities of daily living; $*$ = intragroup difference.

\section{Discussion}

The main results reveal that neurofunctional training is more effective than resistance training in terms of spatial and temporal gait parameters. Both treatments were effective in regard to quality of life, though neurofunctional training was slightly superior to resistance training.

Physical therapy is complementary to pharmacological and surgical treatment in handling signs and symptoms of PD, because exercising improves synaptic strength and influences neurotransmission, enhancing functional circuits in $\mathrm{PD}$, acting as a fundamental element for motor learning ${ }^{27}$. The problem, however, resides in the fact that interventions are not homogeneous and there is no consensus regarding the ideal approach for each clinical outcome. The most recent meta-analysis has concluded that there is no sufficient evidence to support the idea that one form of physical therapy is superior to another in terms of motor and non-motor symptoms ${ }^{28}$.

Considering the motor symptoms of $\mathrm{PD}$, gait impairment is one of the most incapacitating symptoms and, for this reason, is the object of various studies addressing rehabilitating strategies. Even though physical therapy cannot avoid or reverse the progressive nature of the disease, it can minimize the deficiencies it causes ${ }^{3,29,30}$.

The results of the present study are in agreement with previous works. A systematic review and meta-analysis ${ }^{31}$ included 29 clinical trials that used the main approaches: therapy based on Bobath's concept, balance training, gait training with visual, sensory and auditory cues, and proprioceptive neuromuscular facilitation. As a result, improvement was verified in terms of gait speed, balance, agility, and scores obtained on the UDPRS. More recently, a rehabilitation program designed to improve mobility, balance and gait, enhanced with different external cues $^{32}$, (similar approaches developed and implemented in this study) found that the intervention group improved the number of steps, time of distance walked, and stride length immediately after the program and in one-month follow-up.

Another therapeutic widely used approach is resistance training. Various studies report its effects on motor function, muscle strength and resistance ${ }^{33,34}$. Even though evidence supports the use of this type of training for motor function measures, little is known about its effects on the gait of individuals with PD.

In this sense, a systematic review with meta-analysi ${ }^{35}$ of progressive resistance training addressing 172 individuals between mild and moderate stages of PD, showed no improvement in gait after an average of 16 weeks of progressive resistance training; only the muscle strength of lower limbs improved. Additionally, another studies ${ }^{36}$, and a recent meta-analysis ${ }^{12}$ verified that moderate progressive resistance training can improve muscle strength, balance, and motor symptoms; however no improvement was observed in gait, balance or quality of life when compared to groups who received non-resistant exercises in the control group. Based on these findings, one cannot conclude that RT has a beneficial effect on the gait of individuals with PD, hence, improved muscle strength does not necessarily have a positive impact in gait. In this study, the RT group showed only modest improvement in stride length. We can speculate that this happened because the RT intervention did not include task-specific exercises and even if the strength increased the patients were unable to transfer to the functional activities, such as gait. 
In regard to the application of the different treatments in this study, note that the treatment the NT group received was task-oriented based on specific training. The exercises took into account weight transferences between lower limbs, representation of gait in daily life through activities that encouraged divided attention (double task), the use of visual cues to train a more challenging type of gait, using greater attention demands, and balance exercises to promote greater safety among patients. We believe that the involvement of various sensorial resources eases sensory-motor integration and recovery of function and ability (gait), which the training is intended to promote.

This is due to the nervous system's plastic ability to respond in a more dynamic and varied way to sensorial and motor stimuli, varied experiences and learning, as these are an integrative part of a therapy richer in resources. For this reason, rehabilitation techniques should promote sensorial and motor stimuli with increasing levels of skills to encourage long-lasting plastic phenomena that functionally result in beneficial changes ${ }^{37}$.

In relation to the improvement of quality of life, the physical therapy interventions were effective in both groups. Analysis of the questionnaires' domains showed varied results, sometimes indicating improved quality of life in the RT group and sometimes in the NT group.

These results may be explained by the fact that, even though the physical therapy protocols are different between groups, the way treatments were implemented is similar in regard to how sessions were supervised, direct care provided to patients, and the fact training was implemented in groups, which enables the patients to socialize, interact and exchange experiences, improving their social and emotional functions and, consequently, their quality of life. It seemed, in the quality of life assessment, to be essential for patients to have a feeling of belonging to a group specialized in PD rather than to the technique employed, since exercises practiced in groups improve the quality of life of patients with $\mathrm{PD}^{38}$.

Different physical therapy protocols aimed to improve quality of life are described in the literature showing the benefit of exercises in preserving functionality and quality of $\operatorname{life}^{27}$ and studies report that various rehabilitation programs can promote significant positive effects on the quality of life of patients with $\mathrm{PD}^{39}$, and beyond that, changes in the practice of exercises are associated with changes in the quality of life of these patients over the course of two years, with greater impact for the advanced stage of the disease ${ }^{40}$. Therefore, we conclude that different approaches can benefit the quality of life of individuals with PD.

This study's limitations include the fact that results refer to individuals classified as having mild to moderate PD with no cognitive impairment. For this reason results cannot be generalized for patients in the advanced stages of the disease. Losses, common in studies involving human subjects, may have caused type II errors, though this study's results indicate otherwise. A lack of a gold standard to assess gait may also have been a limitation, however, the study validates the importance and clinical applicability of the instrument used here, which involves low-cost implementation.

\section{Conclusion}

The gait of patients with PD improved after the implementation of a specific training protocol, directed and enriched with sensorial resources in comparison to the modest results obtained with the application of resistance training. Both treatments were effective in improving the quality of life of the individuals after the intervention protocols were implemented. These results have implications for the prescription of exercises in rehabilitation programs when the objective is to improve the gait of patients with PD.

\section{References}

1. Peterson DS, Horak FB. Neural control of walking in people with parkinsonism. Physiology. 2016; 31:95-107

2. Pollock AS, Durward BR, Rowe PJ, Paul JP. What is balance? Clin Rehabil. 2000; 14:402-406

3. Horak FB, Frank J, Nutt J. Effects of dopamine on postural control in parkinsonian subjets: scaling, set, and tone. J Neurophysiol. 1996; 75:2380-2396

4. Curtze C, Nutt JG, Carlson-Kuhta P, Mancini M, Horak FB. Levodopa is a double-edgeed sword for balance and gait in people with Parkinson's disease. Mov Disord. 2015; 30:1361-1370

5. Falvo MJ, Schilling BK, Earhart GM. Parkinson's disease and resistive exercise: rationale, review, and recommendations. Mov Disord. 2008; 23:1-11

6. Bloomer RJ, Schilling BK, Karlage RE, Ledoux MS, Pfeiffer RF, Callegari J. Effect of resistence training on blood oxidative stress in Parkinson disease. Med Sci Sports Exerc. 2008; 40:1385-1389

7. Corcos DM, Robichaud JA, David FJ, Leurgans SE, Vaillancourt $\mathrm{DE}$, Poon C, et al. A two-year randomized controlled trial of progressive resistance exercise for Parkinson's disease. Mov Disord. 2013; 28:1230-1240

8. Kelly NA, Ford MP, Standaert DG, Watts RL, Bickel CS, Moellering DR, et al. Novel, high-intensity exercise prescription improves muscle mass, mitochondrial function, and physical capacity in individuals with Parkinson's disease. J Appl Physiol (1985). 2014; 116:582-592

9. Shulman LM, Katzel LI, Ivey FM, Sorkin JD, Favors K, Anderson $\mathrm{KE}$, et al. Randomized clinical trial of 3 types of physical exercise for patients with Parkinson disease. JAMA Neurol. 2013; 70:183-190

10. Silva-Batista C, Corcos DM, Roschel H, Kanegusuku H, Gobbi LT, Piemonte ME, et al. Resistance training with instability for patients with Parkinson's disease. Med Sci Sports Exerc. 2016; 48:1678-1687

11. Monticone M, Ambrosini E, Laurini A, Rocca B, Foti C. In-patient multidisciplinary rehabilitation for Parkinson's disease: A randomized controlled trial. Mov Disord. 2015; 30(8):1050-8.

12. Ginis P, Nackaerts E, Nieuwboer A, Heremans E. Cueing for people with Parkinson's disease with freezing of gait: A narrative review of the state-of-the-art and novel perspectives. Ann Phys Rehabil Med. 2017; S1877-0657(17)30404-9.

13. Strouwen C, Molenaar EALM, Münks L, Keus SHJ, Zijlmans JCM, Vandenberghe W, et al. Training dual tasks together or apart 
in Parkinson's disease: Results from the DUALITY trial. Mov Disord. 2017; 32(8):1201-1210.

14. Conradsson D, Nero H, Löfgren N, Hagströmer M, Franzén E. Monitoring training activity during gait-related balance exercise in individuals with Parkinson's disease: a proof-of-concept-study. BMC Neurol. 2017; 17(1):19.

15. Marinelli L, Crupi D, Di A, Bove M, Eidelberg D, Abbruzzese $\mathrm{G}$, et al. Learning and consolidation of visuo-motor adaptation in Parkinson's disease. Park Relat Disord [Internet]. 2009;15(1):6-11. Available from: http://dx.doi.org/10.1016/j. parkreldis.2008.02.012

16. Schlenstedt C, Paschen S, Kruse A, Raethjen J, Weisser B, Deuschl G. Resistance versus balance training to improve postural control in Parkinson's disease: A Randomized Rater Blinded Controlled Study. PLoS One. 2015; 10(10):e0140584.

17. Hughes AJ, Daniel SE, Kilford L, Lees AJ. Accuracy of clinical diagnosis of idiopathic Parkinson's disease: a clinico-pathological study of 100 cases. JNeurolNeurosurg Psychiatry. 1992; 55(3):181-184.

18. Hoehn MM, Yahr MD. Parkinsonism: onset, progression and morbidity.Neurology. 1967; 17(5):427-42.

19. Schulz, KF, Altman DG, Moher D. CONSORT 2010 statement: updated guidelines for reporting parallel group randomised trials. BMJ. 2010; 340:c332.

20. Fahn S, Elton RL, UPDRS Development Committee. Unified Parkinson's Disease Rating Scale. In: Fahn S, Marsden CD, Calne DB, Goldstein M, eds. Recent Developments in Parkinsonvelopments. Florham Park, NJ: Macmillan; 1987;153-63.

21. Folstein MF, Folstein SE, McHugh PR. "Mini-mental state": a practical method for grading the cognitive state of patients for the clinician. J Psychiatr Res. 1975; 12(3):189-98.

22. Romero VM. Análise das variáveis de distância da marcha de pacientes com acidente vascular encefálico. Conscientiae Saude. 2008; 7(3): 324-9.

23. de Boer AG, Wijker W, Speelman JD, de Haes JC. Quality of life in pacients in Parkinson's disease: development of a questionnaire. J Neurol Neurosurg Psychiatry. 1996; 61:70-74.

24. Goulart F, Pereira LX. Uso de escalas para avaliação da doença de Parkinson em fisioterapia. Fisioter Pesq. 2005;11(1):49-56.

25. Souza RG, Borges V, Silva SMCA, Ferraz HB. Quality of life scale in Parkinson's disease PDQ-39 - (Brazilian Portuguese version) to assess patients with and without levodopa motor fluctuation. ArqNeuropsiquiatr. 2007; 65(3-B):787-791.

26. Cohen J. Statistical Power Analysis for the Behavioral Sciences. Second edition. Hillsdale: Lawrence Earlbaum Associates, 1988.

27. Abbruzzese G, Marchese R, Avanzino L, Pelosin E. Rehabilitation for Parkinson's disease: Current outlook and future challenges. Parkinsonism RelatDisord.2016; 22 Suppl 1:S60-4.

28. Tomlinson CL, Herd CP, Clarke CE, Meek C, Patel S, Stowe R, et. al. Physiotherapy for Parkinson's disease: a comparison of techniques. Cochrane Database Syst Rev. 2014; 17(6) CD002815.

29. Schenkman M, Hall DA, Barón AE, Schwartz RS, Mettler P, Kohrt WM. Exercise for people in early-or mid-stage Parkinson disease: a 16-month randomized controlled trial. PhysTher. 2012; 92(11):1395-410.

30. Ebersbach G. Rehabilitative therapy in patients with Parkinson's disease. Basal Ganglia.2014; 4(1):19-23.
31. Tomlinson CL, Patel S, Meek C, Herd CP, Clarke CE, Stowe R, et al. Physiotherapy intervention in Parkinson's disease: systematic review and meta-analysis. BMJ. 2012; 345:e5004.

32. Stozek J, Rudzinska M, Pustulka-Piwnik U, Szczudlik A. The effect of the rehabilitation program on balance, gait, physical performance and trunk rotation in Parkinson's disease. Aging ClinExp Res. 2016; 28(6):1169-1177.

33. Brienesse LA, Emerson MN. Effects of Resistance Training for People With Parkinson's Disease: a systematic review. J Am Med Dir Assoc. 2013; 14(4):236-41.

34. Roeder L, Roeder L, Costello JT, Smith SS, Stewart IB, Kerr GK. Effects of Resistance Training on Measures of Muscular Strength in People with Parkinson's Disease: A Systematic Review and Meta-Analysis. PloS One. 2015; 10(7):e0132135.

35. Tillman A, Muthalib M, Hendy AM, Johnson LG, Rantalaijnen T, Kidgell DJ. Lower limb progressive resistance training improves leg strength but not gait speed or balance in Parkinson's disease: a systematic review and meta-analysis. Front Aging Neurosci. $2015 ; 7: 40$.

36. Rafferty MR, Prodoehl J, Robichaud JA, David FJ, Poon C, Goelz LC, et al. Effects of 2 years of exercise on gait impairment in people with Parkinson disease: The PRET-PD Randomized Trial. J NeurolPhysTher. 2017;41(1):21-30.

37. Santos SM, Silva RA, Terra MB, Almeida IA, Melo LB, Ferraz HB. Balance versus resistance training on postural control in patients with Parkinson's disease: a randomized controlled trial. Eur J PhysRehabil Med. 2017; 53(2):173-83.

38. King LA, Wilhelm J, Chen Y, Blehm R, Nutt J, Chen Z, et al. Effects of Group, Individual, and Home Exercise in Persons With Parkinson Disease: A Randomized Clinical Trial. J NeurolPhysTher. 2015; 39(4):204-212.

39. Silva FC, lop RR, Santos PD, Melo LMAB, Filho PJBG, Silva R. Effects of physical-exercise-based rehabilitation programs on the quality of life of patients with Parkinson's disease: a systematic review of randomized controlled trials. J Aging Phys Act. 2016;24(3):484-96.

40. Rafferty MR, Schmidt PN, Luo ST, Li K, Marras C, Davis TL, et al. Regular Exercise, Quality of Life, and Mobility in Parkinson's Disease: A Longitudinal Analysis of National Parkinson Fo undation Quality Improvement Initiative Data. J Parkinsons Dis. 2017;7(1):193-202.

\section{Corresponding author}

*Suhaila M. Smaili, Department of Physiotherapy, State University of Londrina, Av. Robert Koch 60, 86.038-350, Londrina, PR, Brazil.

Email: suhailaneuro@gmail.com

Manuscript received on August 25, 2017

Manuscript accepted on February 16, 2018

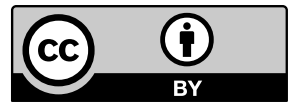

Motriz. The Journal of Physical Education. UNESP. Rio Claro, SP, Brazil - eISSN: 1980-6574 - under a license Creative Commons - Version 4.0 